\title{
Hydrodynamic simulation for urban drainage project: case study of Niterói
}

\author{
E. A. Nascimento ${ }^{1}$, F. C. B. Mascarenhas ${ }^{2}$, A. H. P. Gomes ${ }^{1,4}$ \\ \& A. Verwey ${ }^{3}$ \\ ${ }^{1}$ Programa de Pós-Graduação em Engenharia Civil- UFF, Brazil \\ ${ }^{2}$ Universidade Federal do Rio de Janeiro, COPPE/UFRJ, Brazil \\ ${ }^{3}$ WL-Delft Hydraulics Institute, The Netherlands \\ ${ }^{4}$ Fundação Rio Águas, Rio de Janeiro, Brazil
}

\begin{abstract}
Flooding in urban areas results mainly from both soil imperviousness and bad drainage projects. This means that without proper drainage and without adequate maintenance, floods always happen. On the other hand, traditional procedures applied to calculate urban drainage do not give good results when compared with advanced technologies available at universities and at research centres all over the world. Based on those considerations, this paper presents a computer simulation that aims to correct the Santo Antonio creek drainage problems, which is part of an urban basin located at the ocean zone of the city of Niteroi, in Rio de Janeiro State, Brazil. The software named "Sobek", developed by the WL-Delft Hydraulic Institute, was applied to simulate the proposed drainage networks. The results show that it is possible to avoid flooding by constructing on site reservoirs to retain part of the rainwater. It was suggested that 2400 litres of rainwater per residence was stored in order to reduce the runoff. Keywords: urban drainage, computational simulation and flood control.
\end{abstract}

\section{Introduction}

In order to fulfil the requirements of Niteroi City Hall, a drainage study was developed in Piratininga district aiming to solve, through least intervention and low cost, the flooding problems that have frequently caused damage and worry to the inhabitants of that area. The studied area is related to the Santo Antonio creek, which drains an area of about 188 ha, limited by the hills of Peca and 
Jacare, being a contribution to the Piratininga coastal lagoon. The basin has a large established urban residential area, having medium occupation density.

The aforementioned creek is nowadays completely uncharacterised by progressive rectifications, bypasses and canalisations. Along its extension of 1890 metres, closed galleries constitute the major part. The final stretch, near Raul Travassos street, appears in the form of an open channel with an earth bottom and concrete vertical walls.

The majority of the streets of the basin have no pavement and the drainage system, with low bottom slope pipes and intakes by openings in the curb inlets, or street inlets, suffer frequent silting. At the lower stretches of the streets flooding occurs at least once a year, inundating the habitations, fig. 1, and causing enormous damage and hazards to the inhabitants.

As the area is close to the Piratininga coastal lagoon, the outflow conditions become much limited, being subjected to the effects of tidal variations that cause backwater in the final stretches of the galleries.

Due to this situation, which was very unfavourable for conception of the drainage nets, it was practically impossible to analyse the problem through traditional methods.

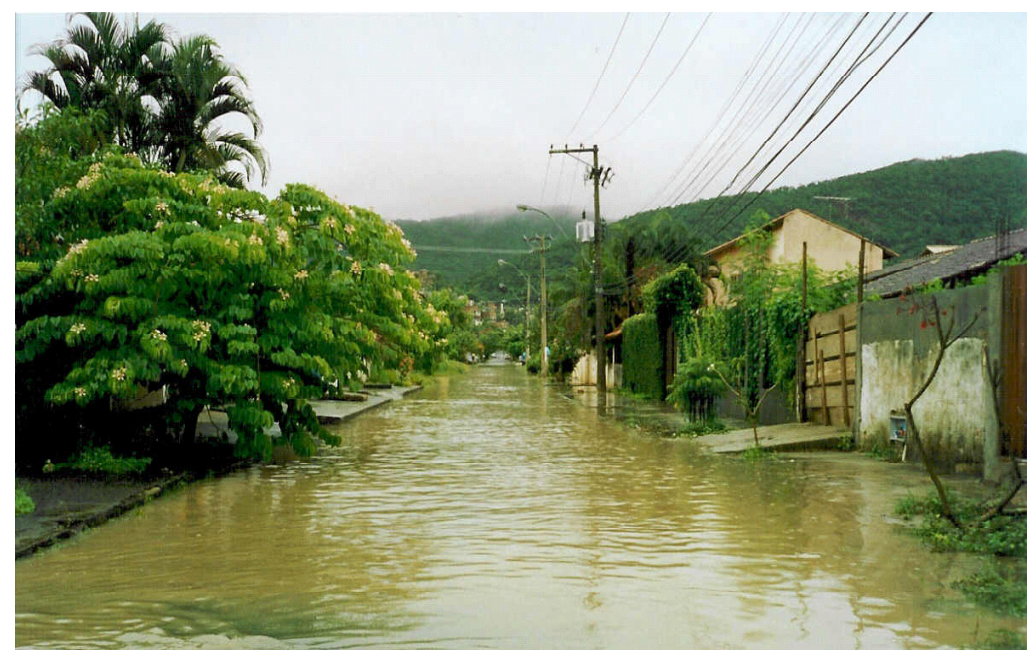

Figure 1: Santo Antonio creek drainage - December/2002.

\section{Methodology}

\subsection{Hydrological studies}

As in traditional hydraulic studies, in the hydrodynamic simulation the hydrological data are of utmost importance for the watershed diagnostics as well for the drainage system project. Their fundamentals with respect to 
measurements and careful basin observations are invaluable in order that the input model data does not result in large and spurious errors in the results.

Due to lack of local rainfall and fluvial information the model was not calibrated from measured field data. The artifice that was used was that the discharges for the basin were obtained from conventional methods taking as a basis projects and hydraulic studies already developed for the region. The discharge values were adopted as boundary conditions for the model of simulation of the galleries flow.

For the evaluation of the discharges from rainfall of the micro-drainage net the Modified Rational Method was adopted, which is presently being used by the Rio Aguas Foundation, an organisation of the Rio de Janeiro City Hall, for areas less than 100 ha. For the adjacent contributing basin the Unit Triangle Hydrograph Method was applied [1].

The considered rainfall equation in the hydrological study was that for the station of Niteroi, turned regional by Pfafsteter [2]. This estimate resulted in rainfall intensities of $153.52 \mathrm{~mm} / \mathrm{h}$ and $126.28 \mathrm{~mm} / \mathrm{h}$, when calculated for durations of 10 and 15 minutes, respectively, and a time recurrence of 10 years.

For the discharge evaluation by the Rational Method, the average runoff coefficient $\mathrm{C}=0.5$ was adopted, while for the Unit Hydrograph Method the average $\mathrm{CN}=65 \%$ was adopted. The impervious area was taken as $35 \%$ of the total basin area.

Assuming a total storage of about 1200 cubic metres, a damping for the design discharge was obtained, decreasing the maximum discharge to 6.92 cubic metres per second. Those indexes were evaluated from the storage of 2.4 cubic metres of rainfall per residence, in a total of 500 habitations (Nascimento [3]). This procedure will be reached through the installation of gutters at the roofs and the routing of water in the direction of the reservoirs, and that volume will be drained posterior to the storm drains or reused in activities that do not compromise human health.

\subsection{Hydraulic evaluation procedure}

The traditional methods for hydraulic net calculations assume that the flow in channels and pipes is steady and uniform, in order to allow the use of empirical expressions like the Manning and Hazen-Williams, for instance. On the other hand, it is well known that natural flows occur in an unsteady way. With computer advances and the consequent increasing use of numerical methods, particularly for solving differential partial equations, it has been possible to represent mathematically the hydraulic phenomena in a more realistic way. In the present work, the flows inside the galleries are represented by a Saint-Venant type equation as a result of combining the continuity and momentum onedimensional equations, as follows [4,5]:

$$
\frac{\partial A}{\partial t}+\frac{\partial Q}{\partial x}=q
$$




$$
\frac{\partial Q}{\partial t}+\frac{\partial}{\partial x}\left(\frac{Q^{2}}{A}\right)+g A \frac{\partial y}{\partial x}+\frac{g Q|Q|}{C^{2} R A}-W \frac{\tau}{\rho}=0
$$

where

$Q$ - flood water discharge at the drainage cross section $\left(\mathrm{m}^{3} / \mathrm{s}\right)$

$y$ - water surface elevation (m)

$A$ - wetted area of the pipe transverse section $\left(\mathrm{m}^{2}\right)$

$W$ - flow width (m)

$x, t$ - independent variables of space and time $(\mathrm{m}, \mathrm{s})$

q - lateral discharge per unit length $\left(\mathrm{m}^{2} / \mathrm{s}\right)$

$g$ - gravity acceleration $\left(\mathrm{m} / \mathrm{s}^{2}\right)$

$C$ - Chezy coefficient $\left(\mathrm{m}^{1 / 2} / \mathrm{s}\right)$

$R$ - hydraulic radius $(\mathrm{m})$

$\tau$ - wind stress $\left(\mathrm{N} / \mathrm{m}^{2}\right)$

$\rho$-specific mass of the water $\left(\mathrm{kg} / \mathrm{m}^{3}\right)$

In the preceding equation, the first term is related to inertia effects, the second term is the convection one, the third term is related to the water level inside the pipe, the fourth term is due to friction between the fluid and the pipe's bed and the last one is related to the wind friction.

\section{Simulations}

For the hydrodynamic simulation of the drainage net the software Sobek was used, developed by the Institute WL-Delft Hydraulics, from the Netherlands, which allows the representation of the unsteady free surface and pressure-pipe flows. In this way, it became possible to analyse the conditions of flux both in the existing and in the projected galleries, considering different hydrological scenarios and identifying the critical points of the system.

Several simulations were developed and performed considering the hydrological conditions already presented as well the existing and the projected galleries.

The estimated total basin discharge of $9.92 \mathrm{~m}^{3} / \mathrm{s}$, corresponding to the 10 year recurrence design rainfall and 15 minutes of duration, was shown to be much larger than the existing galleries capacity, whose conveyance is around 2.00 $\mathrm{m}^{3} / \mathrm{s}$. The simulation has stressed those conditions through the graphical outputs and through the animation tools of the software, confirming the risk of the residences' inundation.

Then, different drainage combinations were simulated, including the construction of new galleries and the use of the street beds themselves acting as channels for the flow of the galleries excess waters. All the alternatives have considered also the damping, at the habitations viewpoint, for the decreasing of the total watershed discharge as already mentioned.

The flow in the pipe before it is totally completed is shown in fig. 2, and after it is transferred from the pipes to the streets' surface is shown in fig. 3. 


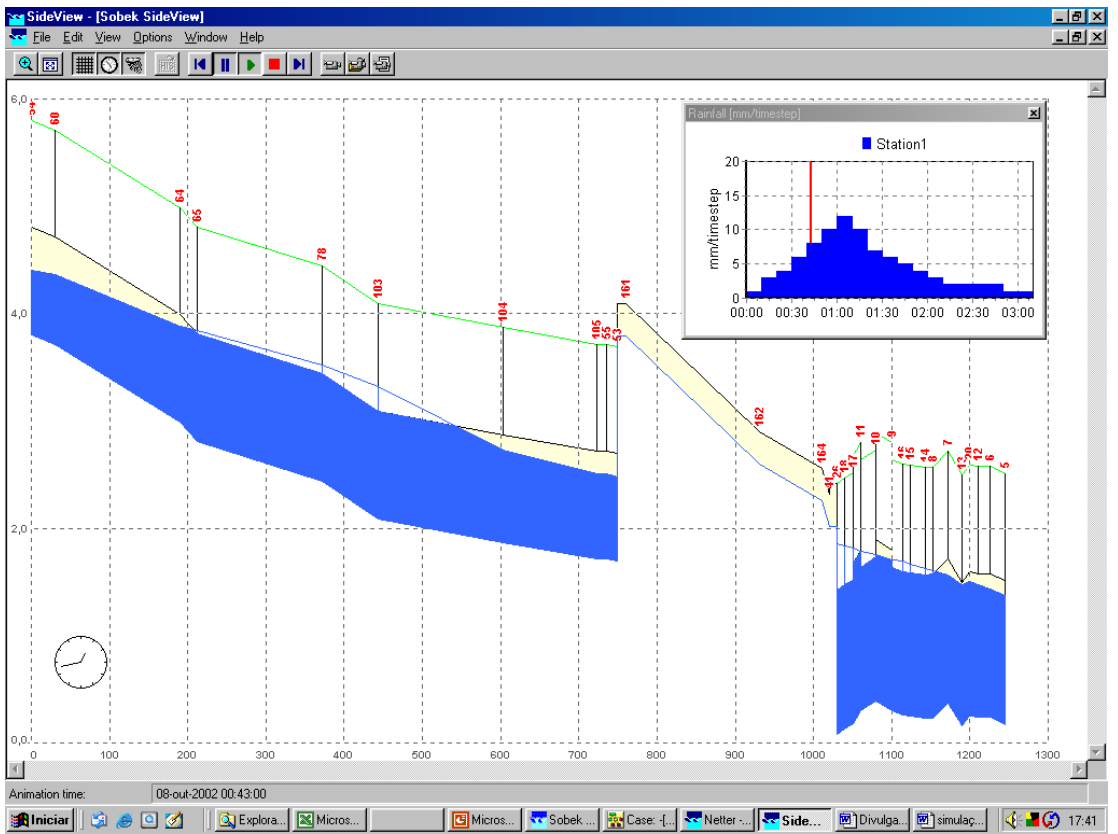

Figure 2: $\quad$ Hydrodynamic simulation - flow in the gallery.

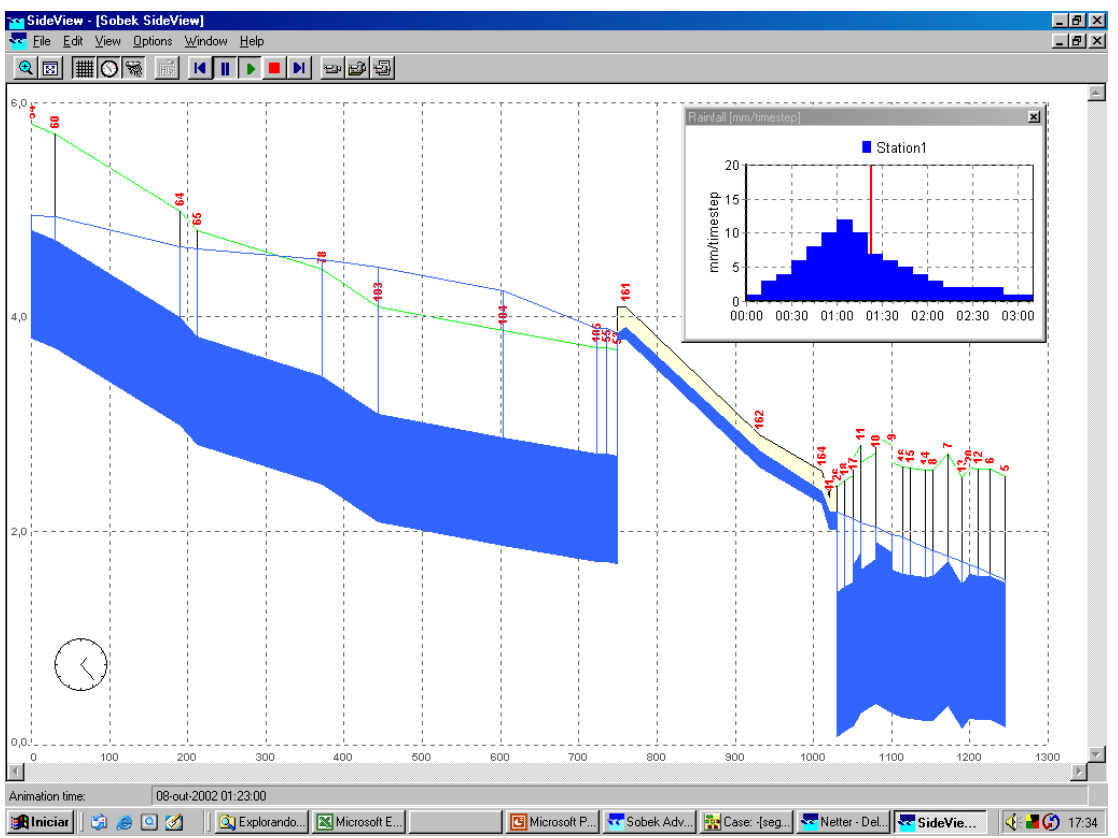

Figure 3: Hydrodynamic simulation - flow in the gallery and on the street. 


\section{Conclusions}

The simulation results showed that the minimum intervention, adopting a flood problem recurrence time of 10 years at Santo Antonio creek, would be the construction of a new gallery with a diameter of $1 \mathrm{~m}$ and $1500 \mathrm{~m}$ length, in parallel to the existing gallery. As a complement, the streets where those galleries are installed should have their grade adjusted in such a way as to allow the surface flow to exceed the drainage net discharge. In those conditions, and assuming the storage of 2400 litres in at least 500 habitations located at points upstream of the inundation critical areas, the maximum water level observed in the simulations was not enough to reach the interior of the residences.

It must be stressed that the goal of this work was to find an adequate solution to the drainage problem within the limitations of resources of the City Hall, including the participation of the community through the construction of residential reservoirs. The simulation tool makes it possible to analyse several alternatives, which would be impossible to solve through traditional evaluation methods of urban drainage projects.

\section{References}

[1] Tucci, C.E.M., Hydrology: Science and Application, UFRGS Publishing, Brazil, 1993, (in Portuguese).

[2] Pfafsteter, O., Intense Rainfall in Brazil, National Department of Works and Sanitation, Brazil, 1957, (in Portuguese).

[3] Nascimento, E.A., Computational Modelling for the Hydrodynamic Study of Drainage Nets using the software Sobek, Thesis for Full Professor Examination, Fluminense Federal University, Niteroi, 2003, (in Portuguese).

[4] Chow, Ven Te, Open Channel Hydraulics. Mac Graw Hill Book Company, New York, 1959.

[5] Veira da Silva, R.C., Mascarenhas, F.C.B. \& Miguez, M.G., River Hydraulics, COPPE-UFRJ Publishing, Brazil, 2003, (in Portuguese). 